\title{
Study Risk of Hepatic Encephalopathy in Diabetic Patients with Decompensated Cirrhosis
}

\author{
KHALED M. DARWISH, M.D.; ABEER A. SHAHBA, M.D.; AMAL A. SELIM, M.D. and \\ MARIAM N. EL-MAHALAWY, M.Sc.
}

The Department of Internal Medicine, Faculty of Medicine, Tanta University

\begin{abstract}
Background: Hepatic Encephalopathy (HE) is a serious complication in patients with cirrhotic liver disease. Diabetic patients with decompensated cirrhosis are suffering more than non-diabetic patients.

Patients and Methods: This study included 100 patients with decompensated cirrhosis and they were classified into 2 main groups:

Group (A): Diabetic with decompensated cirrhosis. They were further classified into diabetic patients and patients with Impaired Glucose Tolerance (IGT).

Group (B): Non-diabetic with decompensated cirrhosis.

Then we compared the risk of hepatic encephalopathy between the 2 groups.

Results: Diabetic patients are at higher risk for HE than patients with IGT and both are at higher risk than non-diabetic patients.

Conclusion: Patients with cirrhosis should be screened for IGT and diabetes at frequent intervals so that early intervention can be initiated when required.
\end{abstract}

Key Words: Decompensated cirrhosis - Hepatic encephalopathy-Diabetes mellitus.

\section{Introduction}

LIVER cirrhosis is a major health problem which represents the final common pathway of wide variety of chronic liver diseases [1]. It is a histological diagnosis based on fibrosis and replacement of normal architecture by abnormal nodules [2] . Common causes of cirrhosis are chronic viral infection as viral hepatitis C, B and D, alcoholic liver cirrhosis and secondary biliary cirrhosis [3]

Patients with compensated cirrhosis do not have symptoms related to their cirrhosis, but patients with decompensated cirrhosis have symptomatic

Correspondence to: Dr. Khaled M. Darwish, The Department of Internal Medicine, Faculty of Medicine, Tanta University complications [4]. These patients are categorized according to Child Pugh Score [5] or MELD Score $[6,7]$.

Hepatic Encephalopathy (HE) is the occurrence of confusion, altered level of consciousness and coma as a result of liver failure [8]. It is caused by accumulation in the blood stream of toxic substances that are normally removed by the liver. The diagnosis of hepatic encephalopathy requires the presence of impaired liver function and the exclusion of an alternative explanation for the symptoms. Attacks are often caused by another problem, such as infection or constipation $[\mathbf{8 , 9 ]}$.

It is a spectrum ranging from Minimal Hepatic Encephalopathy (MHE) without recognizable clinical symptoms or signs, to overt hepatic encephalopathy $(\mathrm{OVH})$ with risk of cerebral edema and death or just poorer prognosis $[\mathbf{1 0 , 1 1 ]}$.

Hepatic encephalopathy is reversible with treatment by the suppression of the production of the toxic substances in the intestine and is most commonly done with the laxative lactulose or with non-absorbable antibiotics and the treatment of any underlying condition. In particular settings, such as Acute Liver Failure (ALF), the onset of encephalopathy may indicate the need for a liver transplant $[\mathbf{8 , 1 2}]$.

The liver has an important role in carbohydrate metabolism since it is responsible for the balance of blood glucose levels by means of glycogenesis and glycogenolysis [13-18]. So, up to $96 \%$ of patients with cirrhosis may be glucose intolerant and $30 \%$ may be clinically diabetic $[\mathbf{1 9 , 2 0}]$. On the other hand, the diabetes which develops as a complication of cirrhosis is known as "hepatogenous diabetes" [13] . 
Diabetes Mellitus (DM) could increase the risk of HE by constipation, increased gastric transit time, increased orocecal time, intestinal bacterial overgrowth and the increased glutaminase activity. Classically, hyperammonemia has been considered the main trigger of HE. However, in recent years the role of systemic inflammatory response has grown in importance, particularly tumour necrosis factor alpha (TNF ct) and Interleukin 6 (IL-6), as synergistic factors. Both are stimulated by DM and insulin resistance [21]

\section{Patients and Methods}

In the period from April 2016 to November 2016, a total of 100 patients presented to Tanta University Hospitals and El-Menshawy Hospital with manifestations of decompensated liver cirrhosis such as ascites, jaundice, lower limb oedema, clubbing of fingers. 57 patients presented with hepatic encephalopathy while 43 patients not.

\section{Inclusion criteria:}

Patients with decompensated cirrhosis showing signs of decompensation as: Jaundice, palmar erythema, spider navaei, ascites, fetor hapatis etc.

\section{Exclusion criteria:}

- Patients with compensated cirrhosis showing no signs of complications.

- Patients of type 1 DM.

\section{Consent:}

An informed written consent was taken from every patient included in this study.

All patients in the study were subjected to:

A- Full history taking regarding age, sex, any previous attacks of haematemesis or melena and any other disease. History of diet was also taken from patients.

B- Full clinical examination with special emphasis on stigmata of chronic liver disease.

C- Laboratory investigations including:

a- Routine laboratory investigations:

- Complete blood count.

- Liver function tests [AST, ALT, alkaline phosphatase, serum bilirubin (total, direct and indirect), total protein and serum albumin].

- Prothrombin time and activity, INR (International Normalized Ratio).

- Fasting Blood Sugar (FBS).

- Post prandial blood sugar.
- Kidney function tests (serum creatinine and blood urea).

b- Specific laboratory investigations:

- HbA1c.

- Glucose tolerance test (for border line FBS).

- Lipid profile for patients with diabetes or IGT.

- Ascitic fluid aspiration and analysis for Total Leucocytic Count (TLC) for patients with SBP.

- Viral markers: HCV Ab, HBsAg.

-PCR: For patients with HCV Ab +ve or HBsAg +ve.

D- Radiological investigations:

- Pelviabdominal ultrasonography.

- Fibroscan: Only for patients with either HCV or HBV.

E- Neurospychometric tests: Two from the following tests were done to every patient:

- Number Connection Test-A (NCT-A).

- Number Connection Test-B (NCT-B).

- Digit Symbol Test (DST).

- Line tracing test.

- The serial dotting test.

According to clinical examination and investigations the patients were classified into two groups: Group (A): Diabetic with decompensated cirrhosis: 76 patients.

It was found that 48 patients were diabetic (on insulin therapy, FBS $>126 \mathrm{mg} / \mathrm{dl}, \mathrm{PP} 2 \mathrm{~h}>200$ and HbA $1 \mathrm{c}>6.5 \%$ ) while 28 patients had Impaired Glucose Tolerance (IGT) (No past history of DM, FBS $>110$ and $<126$, PPBS $>140$ and $<200$ and $\mathrm{HbA} 1 \mathrm{c}>5.3 \%$ and $<6.5 \%$ ) to whom glucose tolerance test was done.

Lipid profile was done to patients in this group to assess for metabolic syndrome or NAFLD and its relation with DM.

Group (B): Non-diabetic with decompensated cirrhosis: 24 patients.

They had no past history of diabetes, FBS $<110$, PPBS <140 and HbA1c <5.3\%.

Patients with HE were detected either by disturbed conscious level or inability to perform neurospychometric tests correctly. Also, there was a strength on precipitating factor of encephalopathy in each patient such as high protein diet, haematemesis or melena, SBP or urinary tract infection. 


\section{Statistical analysis:}

Statistical presentation and analysis of the present study was conducted using the mean, standard deviation and chi-square test by SPSS V.20.

Outcome parameters: The presence or absence of $\mathrm{HE}$ in the studied patients and the grade of $\mathrm{HE}$ if present (MHE, grade 1, grade 2, grade 3 or grade 4).

\section{Results}

1- Demographic data: Study population were compared according to age (Table 1) and sex (Table 2 ) with no statistically significant difference as $p$ value was 0.132 and $0.629(>0.05)$ according to age and sex respectively.

Table (1): Comparison between diabetic, IGT and non-diabetic patients according to age

\begin{tabular}{llll}
\hline Age & Diabetic & IGT & Non diabetic \\
\hline Range & 4077 & $42-79$ & $33-76$ \\
Mean \pm SD & $59.96 \pm 8.68$ & $60.32 \pm 9.09$ & $55.71 \pm 10.47$ \\
F-test & & 2.065 & \\
$p$-value & & 0.132 & \\
\hline
\end{tabular}

Table (2): Comparison between diabetic, IGT and non-diabetic patients according to sex.

\begin{tabular}{lllll}
\hline Sex & Diabetic & IGT & Non diabetic & Total \\
\hline Male: & & & & \\
$\mathrm{N}$ & 25 & 17 & 15 & 57 \\
$\%$ & $52.1 \%$ & $60.7 \%$ & $62.5 \%$ & $57.0 \%$ \\
Female: & & & & \\
$\mathrm{N}$ & 23 & 11 & 9 & 43 \\
$\%$ & $47.9 \%$ & $39.3 \%$ & $37.5 \%$ & $43.0 \%$ \\
Total: & & & & \\
$\mathrm{N}$ & 48 & 28 & 24 & 100 \\
$\%$ & $100.0 \%$ & $100.0 \%$ & $100.0 \%$ & $100.0 \%$ \\
Chi-square: & & & & \\
$\chi^{2}$ & & & 0.927 & \\
$p$-value & & & 0.629 & \\
\hline
\end{tabular}

2-Risk of hepatic encephalopathy: There is a total of 57 patients $(57 \%)$ had HE: 33 diabetic patients $(68.8 \%), 20$ patients were IGT patients $(71.4 \%)$ and 4 patients were non-diabetic patients $(16.7 \%)$. Diabetic patients had more liability to be presented by higher grades of HE. $p$ - value is 0.001 $(<0.05)$ so, there was statistically significant difference between patients in the studied groups according to risk of HE. (Table 3 ).

3- Neuropsychometric tests: 43 patients (43\%) could complete neuropsychometric tests: 15 patients were diabetic patients $(31.3 \%), 8$ patients were IGT patients $(28.6 \%)$ and 20 patients were non- diabetic patients (83.3\%). 57 patients $(57 \%)$ couldn't complete neuropsychometric tests: 33 patients were diabetic patients (68.8\%), 20 patients were IGT patients $(71.4 \%)$ and 4 patients were non-diabetic patients $(16.7 \%) . p$-value is 0.001 $(<0.05)$ so, there was statistically significant difference between patients in the studied groups according to neuropsychometric tests. (Table 4).

Table (3): Comparison between diabetic, IGT and non-diabetic patients according to risk of HE.

\begin{tabular}{|c|c|c|c|c|}
\hline $\begin{array}{l}\text { Hepatic } \\
\text { encephalopathy }\end{array}$ & Diabetic & IGT & $\begin{array}{l}\text { Non } \\
\text { diabetic }\end{array}$ & Total \\
\hline \multicolumn{5}{|l|}{ No: } \\
\hline $\mathrm{N}$ & 15 & 8 & & \\
\hline & $34.9 \%$ & $18.6 \%$ & $46.5 \%$ & $100.0 \%$ \\
\hline \multicolumn{5}{|l|}{ MHE: } \\
\hline $\mathrm{N}$ & 4 & 4 & 0 & 8 \\
\hline$\%$ & $50.0 \%$ & $50.0 \%$ & $.0 \%$ & $100.0 \%$ \\
\hline \multicolumn{5}{|l|}{ Grade 1: } \\
\hline & 1 & 4 & 0 & 5 \\
\hline$\%$ & $20.0 \%$ & $80.0 \%$ & $.0 \%$ & $100.0 \%$ \\
\hline \multicolumn{5}{|l|}{ Grade 2: } \\
\hline $\mathrm{N}$ & & & & \\
\hline & $44.4 \%$ & $44.4 \%$ & $11.1 \%$ & $100.0 \%$ \\
\hline \multicolumn{5}{|l|}{ Grade 3: } \\
\hline $\mathrm{N}$ & 16 & 6 & 3 & \\
\hline & $64.0 \%$ & $24.0 \%$ & $12.0 \%$ & $100.0 \%$ \\
\hline \multicolumn{5}{|l|}{ Grade 4: } \\
\hline $\mathrm{N}$ & 8 & & 0 & \\
\hline$\%$ & $80.0 \%$ & $20.0 \%$ & $.0 \%$ & $100.0 \%$ \\
\hline \multicolumn{5}{|l|}{ Total: } \\
\hline $\mathrm{N}$ & 48 & 28 & 24 & 100 \\
\hline$\%$ & $48.0 \%$ & $28.0 \%$ & $24.0 \%$ & $100.0 \%$ \\
\hline \multicolumn{5}{|l|}{ Chi-square: } \\
\hline $\begin{array}{l}\chi^{2} \\
p \text {-value }\end{array}$ & & $\begin{array}{l}31 . \\
0.0\end{array}$ & & \\
\hline
\end{tabular}

*: Denotes significance between diabetic, IGT and nondiabetic patients according to the risk of $\mathrm{HE}$.

Table (4): Comparison between diabetic, IGT and non-diabetic patients according to neuropsychometric tests.

\begin{tabular}{lllll}
\hline $\begin{array}{l}\text { Neuropsychometric } \\
\text { tests }\end{array}$ & Diabetic & IGT & $\begin{array}{c}\text { Non } \\
\text { diabetic }\end{array}$ & Total \\
\hline Can: & & & & \\
$\mathrm{N}$ & 15 & 8 & 20 & 43 \\
$\%$ & $31.3 \%$ & $28.6 \%$ & $83.3 \%$ & $43.0 \%$ \\
Can't: & & & & \\
$\mathrm{N}$ & 33 & 20 & 4 & 57 \\
$\%$ & $68.8 \%$ & $71.4 \%$ & $16.7 \%$ & $57.0 \%$ \\
Total: & & & & \\
$\mathrm{N}$ & 48 & 28 & 24 & 100 \\
$\%$ & $100.0 \%$ & $100.0 \%$ & $100.0 \%$ & $100.0 \%$ \\
Chi-square: & & & & \\
$\chi^{2}$ & \multicolumn{5}{c}{21.011} \\
$p$-value & \multicolumn{5}{c}{$0.001^{*}$} \\
*: Denotes significance between diabetic, IGT and nondiabetic patients \\
according to neuropsychometric test.
\end{tabular}




\section{Discussion}

Hepatic encephalopathy is a major complication of advanced cirrhosis and is associated with poor quality of life and shorter survival in patients with cirrhosis. DM was found to increase the risk of HE. This relationship was explained by the autonomic dysfunction of the bowel which occurs with DM and leads to increase orocecal transit time and also the increasing of the bacterial proliferation in the colon, both leads to increase the production of ammonia by intestinal flora.

There is a two-way association between diabetes and cirrhosis. Patients with diabetes are at increased risk of developing cirrhosis and similarly, patients with cirrhosis and other liver diseases can develop diabetes because of altered carbohydrate metabolism and hepatic dysfunction. The higher risk of cirrhosis in patients with diabetes is due to the fact that diabetics usually have non-alcoholic fatty liver disease, which is a risk factor for the development of cirrhosis. Diabetes is associated with increased morbidity in cirrhosis. Patients with diabetes have more severe liver fibrosis [20].

The principal finding of the present study was that the prevalence of HE was higher in patients with diabetes than without diabetes (33) patients of diabetic had HE $(68.75 \%)$ while 15 patients (31.25\%) hadn't and 20 patients of IGT had HE $(71.43 \%)$ but 8 patients hadn't $(28.57 \%)$ unlike non-diabetic patients only 4 patients had HE (16.67\%) but 20 patients hadn't $(83.33 \%)$ with $p$ value $=0.001$ ). Moreover patients with diabetes were more likely to present with higher grades of HE.

Sigal et al., assessed the association between diabetes and $\mathrm{HE}$ in patients with cirrhosis due to chronic hepatitis $\mathrm{C}$ awaiting liver transplantation and found that HE was present in $95 \%$ of patients with diabetes compared with $78 \%$ of patients without diabetes. Moreover, the severity of $\mathrm{HE}$ as defined by the West Haven criteria, was significantly greater in patients with than without diabetes $(p=0.003)$ [22] .

Similar findings were reported by Kalaitzakis et al. who studied cirrhotic patients irrespective of etiology and found that patients with diabetes took longer to complete Number Connection Test A, one of the many tests used to assess cognitive abnormalities in cirrhotic patients, compared with patients without diabetes and this association remained significant after adjusting for age and Child-Pugh class [23]
Another study was done by Zeeshan et al. [24] The aim of that study was to examine the association of diabetes mellitus with the prevalence and severity of HE in patients with decompensated cirrhosis and determine the impact of age and gender on this relationship. They found that diabetes was associated with $\mathrm{HE}$ even after adjusting for age and gender in a multivariate logistic regression model.

Peter et al., [25] used data from three randomized trials of satavaptan, a vasopressin receptor antagonist that does not affect HE risk, in cirrhotic patients with ascites. The trials included 1198 patients, and they excluded those with HE before or at randomization and followed the remaining patients for the one-year duration of the trials. They found that diabetes increased the risk of firsttime overt $\mathrm{HE}$ among cirrhosis patients with ascites.

Muhammad et al., [26] analyzed the effect of DM on frequency and severity of HE in patients with liver cirrhosis. Three hundred and fifty-two patients with liver cirrhosis were prospectively assessed for severity of liver disease and presence of DM in a multicenter study. Severity of hepatic encephalopathy was higher in patients with diabetes than those without diabetes ( $p$-value for trend 0.01). Cirrhotic patients with type 2 diabetes are more likely to present with HE than cirrhotic patients without type 2 diabetes. Moreover diabetes and age interact to cause increased prevalence of hepatic encephalopathy in decompensated cirrhosis.

Laure Elkrief et al., [27] studied the relationship between DM and liver diseases in general. They found that diabetes is associated with the occurrence of major complications of cirrhosis including ascites, renal dysfunction, HE, bacterial infections and even HCC.

Diego Garcia et al., [28] studied hepatogenous diabetes on March 2016. They found that it associates with increased rate of liver complications including risk of $\mathrm{HE}$ which increased among diabetic patients.

An observational cohort study was made by Michaela et al., [29] on February 2017 included observation of risk of hepatic encephalopathy after Transjugular Intrahepatic Portosystemic Shunts (TIPS). The aim of that study was to compare two groups of patients who did and did not develop overt HE after TIPS, several factors associated with the development of HE after TIPS and among these factors was diabetes mellitus. 


\section{Conclusion:}

Many patients are suffering from liver cirrhosis and its complications such as Hepatic Encephalopathy (HE) which is a fatal one and can affect the physical and intellectual ability and the personality of the patients whether it was MHE or OHE. There is a close relationship between DM and liver diseases. For that, our study aimed to determine the relationship between DM and the risk of HE. We found that diabetic patients are at higher risk for HE than patients with IGT and both are at higher risk than non-diabetic patients. That returns mainly to the hyperammonemia which is caused by the autonomic neuropathy, intestinal dysmotility and bacterial overgrowth caused by DM. Because both diabetes and $\mathrm{HE}$ are associated with poor quality of life and survival in patients with cirrhosis, strict glycemic control and avoidance of precipitating factors for HE (e.g. constipation) must be achieved in all cirrhotic patients with diabetes. Moreover, patients with cirrhosis should be screened for IGT and diabetes at frequent intervals so that early intervention can be initiated when required.

\section{References}

1- GARCIA-TASSO G.: Bacterial infection in cirrhosis Treatment and prophylaxis. J. Hepatol., 42 (1): S85-92, 2005.

2- YILDIRIUM B., SARI R., SEZGIN N.H., et al.: Complement and immunoglobulin levels in serum and ascitic fluid in patients with SBP, malignant ascites and tuberculous peritonitis. South Med. J., 95 (10): 1158-62, 2002.

3- BACON B.R. and LONGO M.: Cirrhosis and its complications. Harrison's principles of Internal Medicine, 18 th edition, Chapter, 308: 2592-602, 2012.

4- DETLEF S. and NEZAM H.: Lancet Seminars: Liver Cirrhosis. Lancet, 371 (9615): 838-51, 2008.

5- CHOLONGITAS E., PAPATHEODORIDIS G.V., VANGELI M., et al.: Systematic review: The model for endstage liver disease should it replace Child-Pugh's classification for assessing prognosis in cirrhosis? Aliment Pharmacol. Ther., 22 (11-12): 1079-89, 2005

6- MALINCHOC M., KAMATH P.S., GORDON F.D., et al.: A model to predict poor survival in patients undergoing transjugular intrahepatic portosystemic shunts. Hepatol., 31 (4): 864-71, 2000.

7- RUSSELL W., ERICK E., RICHARD F., et al.: Model for End-stage Liver Disease (MELD) and allocation of donor livers. Gastroenterol., 124 (1): 91-6, 2003.

8- CASH W.J., McCONVILLE P., McDERMOTT E., et al.: Current concepts in the assessment and treatment of hepatic encephalopathy. Q.J.M., 103 (1): 9-16, 2010.

9- CHUNG R.T., PODOLSKY D.K., KASPER D.L., et al.: Cirrhosis and its complications. Harrison's Principles of Internal Medicine, 16 th edition, Chapter, 308: 1858-69, 2005.
10- TAN H.H., LEE G.H., THIA K.T., et al.: Minimal hepatic encephalopathy runs a fluctuating course: Results from a three-year prospective cohort follow-up study; Singapore Med. J., 50 (3): 255-60, 2009.

11- BOYER T.D., HASKAL Z.J. and American Association for the Study of Liver Diseases: The role of transjugular intrahepatic portal-systemic shunts in the management of portal hypertension. Hepatol., 41 (2): 386-400, 2005.

12- WILLIAM M., ANNE M. and TODD S.: AASLD position paper: The management of acute liver failure. Hepatol., 41 (5): 1179-97, 2005.

13- HOLSTEIN A., HINZE S., THIESSEN E., et al.: Clinical implications of hepatogenous diabetes in liver cirrhosis. J. Gastroenterol. Hepatol., 17 (6): 677-81, 2002.

14- PICARDI A., D'AVOLA D., GENTILUCCI U.V., et al.: Diabetes in chronic liver disease: From old concepts to new evidence. Diabetes Metab. Res. Rev., 22 (4): 27483, 2006.

15- CUSTRO N., CARROCCIO A., GANCI A., et al.: Glycemic homeostasis in chronic viral hepatitis and liver cirrhosis. Diabetes Metab., 27 (4): 476-81, 2001.

16- POSTIC C., DENTIN R. and GIRARD J.: Role of the liver in the control of carbohydrate and lipid homeostasis. Diabetes Metab., 30 (5): 398-408, 2004.

17- BARTHEL A. and SCHMOLL D.: Novel concepts in insulin regulation of hepatic gluconeogenesis. Am. J. Physiol. Endocrinol. Metab., 285 (4): E685-92, 2003.

18-TAPPY L. and MINEHIRA K.: New data and new concepts on the role of the liver in glucose homeostasis. Curr. Opin. Clin. Nutr. Metab. Care, 4 (4): 273-7, 2001.

19- HICKMAN I.J. and MACDONALD G.A.: Impact of diabetes on the severity of liver disease. Am. J. Med., 120 (10): 829-34, 2007.

20- RYM E., MYRIAM C., RANIA H., et al.: Glucose metabolism disorders in cirrhosis: Frequency and risk factors in tunisian population. Results of a Cross-Sectional Study. O. J. Gas., 4 (8): 48858-63, 2014.

21- AMPUERO J., RANCHAL I., DEL M., et al.: Role of diabetes mellitus on hepatic encephalopathy. Metab. Brain. Dis., 28 (2): 277-9, 2013.

22- GARCOVICH M., ZOCCO M.A., ROCCARINA D., et al.: Prevention and treatment of hepatic encephalopathy: Focusing on gut microbiota. World J. Gastroenterol., 18 (46): 6693-700, 2012.

23- KALAITZAKIS E., OLSSON R., HENFRIDSSON P., et al.: Malnutrition and diabetes mellitus are related to hepatic encephalopathy in patients with liver cirrhosis. Liver Int., 27 (9): 1194-201, 2007.

24- ZEESHAN B., NAUMAN A., OSMAN N., et al.: Diabetes mellitus and decompensated cirrhosis: Risk of hepatic encephalopathy in different age groups. J. Diabetes, 5 (4): 449-55, 2013.

25- PETER J., HUGH R., PER K., et al.: Diabetes as a risk factor for hepatic encephalopathy in cirrhosis patients. J. Hepatol., 63 (5): 1133-8, 2015. 
26- MUHAMMAD F., ZEESHAN B., KAMRAN M., et al.: Impact of diabetes mellitus on frequency and severity of hepatic encephalopathy in liver cirrhosis. Endocrine Abstracts, 44: 102, 2016.

27- LAURE E., PIERRE E., SHIV S., et al.: Diabetes Mellitus in patients with cirrhosis: Clinical implications and management. Liver Int., 36 (7): 936-48, 2016.
28- DIEGO G., JOSÉ A., FERNANDO J., et al.: Hepatogenous diabetes: Is it a neglected condition in chronic liver disease? World J. Gastroenterol., 22 (10): 2869-74, 2016.

29- MICHAELA R., VACLAV S., SUNIL K., et al.: Observational cohort study of hepatic encephalopathy after transjugular intrahepatic portosystemic shunt (TIPS). Ann. Hepatol., 16 (1): 140-8, 2017.

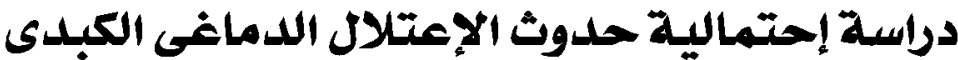 فى مرضى السكرى والتليف الكبدى الغير الغير متكافئ الغئ}

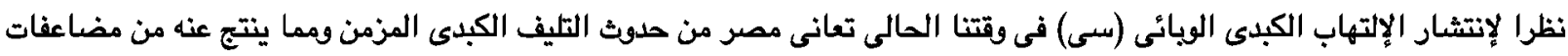

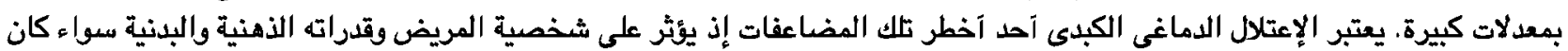
إعتلال دماغى كبدى آدنى آو علنى.

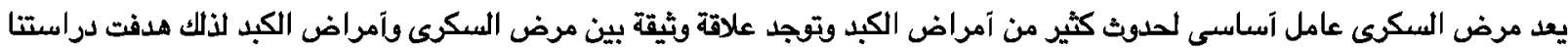

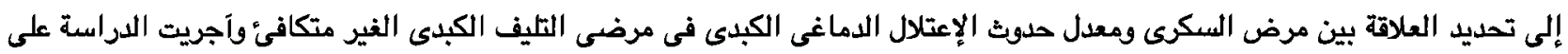

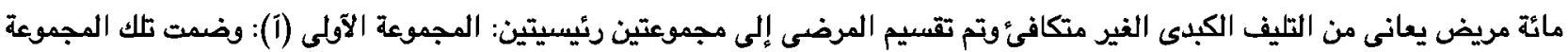

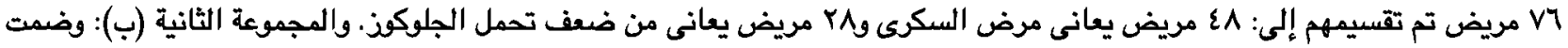

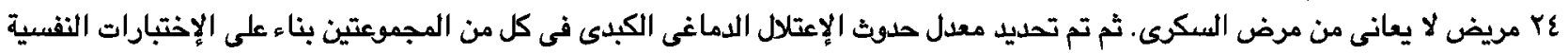

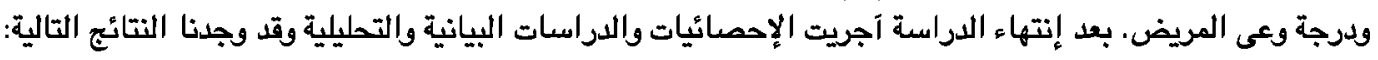

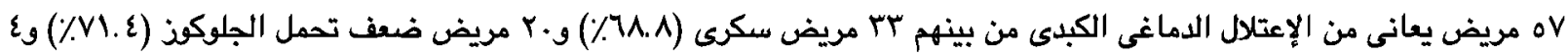

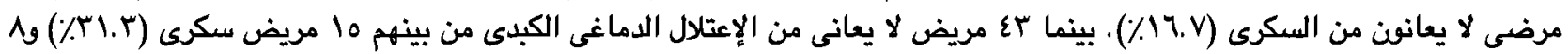

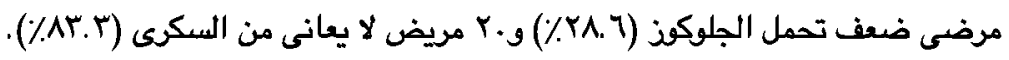

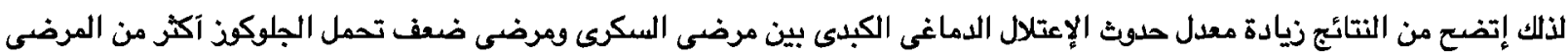

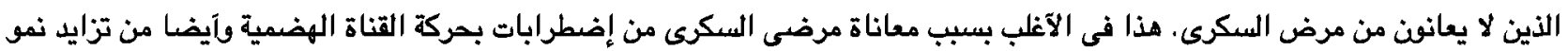

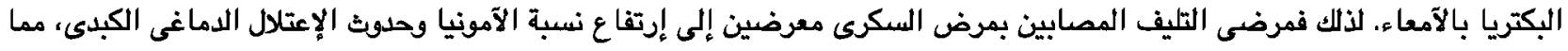

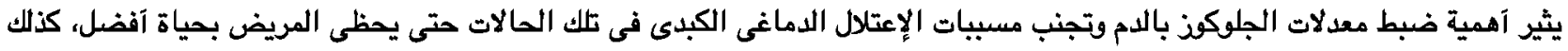

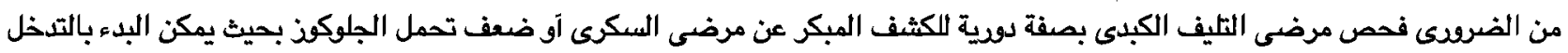

